\section{Turismo de Não-Mercado: perigoso porém libertário}

Non-market Tourism: dangerous however libertarian

Mário Jorge Pires?

RESUMO: O presente trabalho aborda um fenômeno ligado ao fluxo de pessoas, mas grandemente desprezado pela atual bibliografia. Trata-se do turismo de não-mercado. Esta expressão procura colocar parâmetros conceituais nas viagens que se encontram para além das operações turísticas convencionais, mas que são importantes pelo volume e pela intensidade com que ocorrem. A partir de dois cases - Ouro Preto (MG) e a festa de Santo Expedito, em São Paulo-, o tema é desenvolvido com a consciência de ser um esboço do assunto, em virtude de sua alta complexidade.

PALAVRAS-CHAVE: turismo sem agenciamento; turismo espontâneo; fluxos anômalos.

ABSTRACT: The present work approches a phenomenon connected with the flow of people, but greatly overlooked by the current biography. It deals with the tourism of no-market. This expression try to establish a conceptual parameter in journeys that are found beyond the conventional turistic operation, but are important because of the volume and intensity of their occurrence. Departuring from two "cases" - Ouro Preto (MG) and the Party of Saint Expedito in São Paulo - the subject is developed in a counscious manner considering that it is a sketck on this matter, due to its high complexity.

KEYWORDS: tourism without agent; spontaneous tourism; anomalous flow.

1. Professor da Escola de Comunicações e Artes da Universidade de São Paulo. Doutor em Ciências da Comunicação, pela USP. Autor de diversos livros na área de turismo e editor da revista Turismo em Análise. Contato: Rua Prof. Lúcio Martins Rodrigues, 443, Bloco B - Sala 10 - 05508-900 - São Paulo - SP.

\section{Introdução}

O demasiado enfoque nos aspectos econômicos do turismo, importantes porquegeradorese distribuidores de renda, tem camuflado a complexidade do fenômeno que se processa por outras vias, nem sempre fáceis de serem identificadas.

O turismo de não-mercado é uma delas, longe de ser mais uma expressão usada pelo trade ou por antropólogos que se debruçam sobre a área, a expressão procura colocar balizamentos conceituais nos fluxos que se situam à margem das grandes operações.

Não se trata, contudo, do estudo dos chamados excursionistas, já que estes podem fruir de uma destinação, mas, também, usar certos equipamentos turísticos. Igualmente errônea é a idéia de que o turismo de não-mercado atém-se somente a localidades onde, por haver apenas um pequeno fluxo espontâneo, encontram-se distantes das agências de viagem. Embora estas regiões sejam consideradas no âmbito do não-mercado, a experiência tem mostrado que até mesmo em uma grande destinação turística pode ocorrer o mesmo fenômeno.

A bibliografia, até o presente momento, tem se mostrado omissa ao tratar do assunto com a atenção que ele merece, razão pela qual procurou-se, neste artigo, tratar das abordagens que também tangenciam o problema.

Além disso, foram utilizados dois cases que mostram facetas distintas do turismo de não-mercado. $O$ primeiro trata das anomalias que ações deste conteúdo provocam em uma grande destinação, desfazendo-se, assim, a idéia de que se trata de um fenômeno restrito ao fluxo de pessoas de baixa renda. O segundo aborda uma das possibilidades do que se convencionou chamar de turismo religioso, mostrando que é possível haver uma outra noção de lazer, a partir de uma viagem e um motivo de devoção.

\section{A complexidade do fenômeno}

As visões convencionais costumam reduzir a ampla variedade de fenômenos resultantes do fluxo de pessoas a aspectos puramente relacionados ao lado mercadológico.

A OMT estabeleceu parâmetros para definir o fenômeno. Entretanto, embora qualquer área do conhecimento exija esforços no sentido de fixar um balizamento operacional, deve-se ter sempre presente que as definições ortodoxas de turismo da OMT podem e devem ser estudadas e questionadas na academia. Polêmicas e bastante questionáveis são algumas destas definições. Delimitar o período de estada de uma noite, como o mínimo, e de um ano, como o máximo, é uma atitude 
puramente aleatória. Regras imprecisas que mais dificultam do que auxiliam a área e, nesse sentido, também não se justifica uma categorização precisa de propósito de visita, bem como a distância necessária do local de residência, de 160 quilômetros (Cooper et al., 2001).

Oportunas são as observações de Davidson Thomas Lea, ao constatar que os visitantes/turistas são também pessoas que fazem uma viagem de um dia sem pernoite. Mais do que isso: afirma o autor que o turismo pode ser considerado uma experiência extremamente variada ou um processo, e não a receita de um grupo determinado de estabelecimentos semelhantes, a partir do consumo dos visitantes/turistas (Davidson, 2001).

Outra idéia positiva de Cooper é perceber que o turismo é, essencialmente, lazer, não importando o motivo da viagem. Segundo sua visão, a recreação está contida no âmbito do lazer,e, a partir do fluxo contínuo da atividade recreacional, surgem a recreação residencial, o lazer cotidiano, as viagens de um dia e, como categoria distinta (e questionável), o turismo.

As críticas aos autores quelidam com motivo ou motivação de viagem é grande, uma vez que não há base científica para categorizar, para mensurar ou sequer saber qual a proporção de um tipo de motivação em detrimento de outro. Aliás, com a tendência do turista em maximizar as férias ou o tempo livre, as viagens cada vez mais estão tendo um conjunto de motivos/motivações na sua efetivação.

Uma outra vertente são as definições de turismo baseadas na oferta, segundo as quais a indústria turística consiste em todas as empresas, organizações e instalações destinadas a servir as necessidades e os desejos específicos dos turistas (Leiper, 1979).

A debilidade desta vertente é que as empresas, organizações e instalações servem também aos residentes. Para dar corpo a esta idéia, a OMT desenvolveu uma classificação internacional padronizada de atividades turísticas (Standard International Classification of Tourism Activities - SICTA). O raciocínio é simples, basta delimitar em duas camadas as empresas: as que não sobreviveriam sem o turismo e as que sobreviveriam, porém de forma reduzida. Na primeira, entram como exemplos companhias aéreas, hotéis e parques nacionais; já na segunda estariam os restaurantes, os táxis e as atrações locais (Smith, 1989).

Há uma grande simpatia de boa parte dos autores por este tipo de definição, uma vez que ela permite que o turismo seja comparado a outros setores econômicos, além de oferecer um bom suporte conceitual, por levar em conta a chamada região de penumbra entre os extremos do que é ou não turismo.

Todas estas idéias - muitas delas engenhosas - estão longe de explicar as múltiplas faces do turismo, uma vez que a política do turismo não está mais centrada exclusivamente nas finalidades econômicas e técnicas, mas também respeita o meio ambiente e leva em conta as necessidades de todas as pessoas envolvidas. As necessidades turísticas dos indivíduos são múltiplas e não se restringem a uma camada social, daí depreendendo-se que estão envolvidos não somente os que podem pagar pelos equipamentos turísticos convencionais (Krippendorf, 2001).

Assim, na tentativa de compreender mais uma faceta do turismo, surgiu a noção do turismo de não-mercado. Este se caracteriza por usar minimamente os equipamentos turísticos. Isso, porém, não o define completamente, pois lhe falta a espinha dorsal, ou seja, o enfoque não se encontra mais no montante dos gastos deixados nas destinações, mas na fruição decorrente das múltiplas necessidades turísticas dos indivíduos.

Com o foco centrado no homem que quase nada gasta, ele pode ser desprezado pela indústria do turismo, mas, por sua persistência e intensidade como fenômeno, contesta e desafia as definições bem-comportadas. Insolente, agarra-se ao direito humano de viajar pelo prazer, nada preocupado com o aparato custoso dos turistas psicocêntricos de Plog. ${ }^{2}$

Como se pode deduzir, o caráter um tanto libertário do turismo de nãomercado independe de quanto o turista possui no bolso para gastar. Conhecidos no mundo inteiro são os mochileiros de todas as classes sociais, que empreendem viagens a regiões fora de rota e ainda não descobertas pelo turismo convencional, bem como para destinações prestigiosas, provocando por parte delas um certo desprezo e a sempre implícita idéia de que não são bem-vindos (Borg, 2001).

Por outro lado, a noção de turismo de não-mercado presta-se também a regiões ainda inexploradas, que possuem um fluxo espontâneo pequeno. Encontra-se, neste caso, a oportunidade ímpar de se organizar um planejamento turístico sustentável.

\section{A "farofa" dos endinheirados}

O turismo de não-mercado está longe de ser apenas a "invasão" de praias por velhos ônibus lotados de pessoas de baixa renda. É cada vez mais freqüente uma destinação turística receber um fluxo de visitantes que praticam algumas modalidades de esportes radicais e que são detentores de variados equipamentos de suporte. Isso permite aos praticantes manter uma total independência no que concerne a bens e serviços da localidade que os abriga.

2. PLOG, S. C. Why destination areas rise and fall in popularity. Cornell Hotel and Restaurant Quarterly, v. 14, n. 4, 1974. Bem conhecida esta teoria, segundo a qual os turistas americanos poderiam ser classificados em dois extremos inter-relacionados: psicocêntrico e alocêntrico, estando os primeiros acostumados a ter padrões conservadores de viagem. 
Exemplo emblemático é o que ocorre no dia 7 de setembro, na histórica cidade de Ouro Preto (MG). Próximo da hora do almoço, a cidade vê-se tomada por uma parafernália de caminhões e ônibus adaptados para recepcionar algumas dezenas de motoqueiros que percorreram uma longa distância em chão de barro e que, na Praça Tiradentes, além de receberem as premiações dos organizadores, comemoram bebendo e comendo ao redor de churrasqueiras retiradas dos caminhões de apoio. Toda a merenda é trazida de longe. Nada é consumido ou usado oriundo da própria cidade, nem mesmo o banho que, a partir de duchas adaptadas nos veículos, é tomado ali mesmo, com muita alegria e nenhum respeito aos outros turistas, que vêm à cidade para apreciar as suas belas igrejas e museus.

O fato de serem praticantes de um esporte não lhes tira a condição de turistas, pois, além do deslocamento, usam a prestigiosa cidade como destinação final; e um estranho consórcio, no qual se mistura uma espécie de turismo de aventura com o uso do espaço rural, e finalmente, do urbano. Não querem conhecer seus tesouros culturais, mas a sua fabulosa ambiência - que é um atrativo - certamente tem peso na escolha e é usada para a apoteose final.

A presença do evento não agrega nenhum valor cultural à destinação, nem ao menos prestígio político às autoridades que lhe dão o apoio. Ao contrário, além do lixo, é visível o estresse que provoca nos residentes e demais turistas, quase impedidos de transitar pela Praça Tiradentes e arredores. Os comerciantes, receosos, costumam trancar os banheiros de cafés, padarias e lanchonetes, uma vez que a "invasão" não lhes traz benefício algum, porém trabalho extra e apoquentações quase inevitáveis.

Não usam quaisquer equipamentos turísticos e também nada consomem, não por falta de dinheiro, mas por não se encaixarem no inventário mercadológico das diversas formas de turismo.

Com este exemplo, fica evidente que o turismo de não-mercado não é necessariamente a humanização libertária do turismo, avesso às regras relativamente antigas e enfadonhas de mercado. Pode ser o direito de ir e vir, e também de fruir uma destinação, mas pode, igualmente, ser um "direito" irrestrito que fere outros direitos; uma prática que atropela, mesquinha e egoísta, que vira as costas para o mercado convencional e, também, para os problemas que gera na própria destinação.

\section{Turismo religioso: o dia de Santo Expedito na cidade de São Paulo}

O turismo de não-mercado pode, igualmente, provocar impactos negativos desprezíveis. No dia 19 de abril de 2005, uma pequena prospecção foi realizada em torno da capela militar de Santo Expedito. Ao todo foram respondidos 52 questionários e a abordagem deu-se de forma aleatória, utilizando-se da fila de mais de três quilômetros que se formava para se entrar na capela. Os objetivos de tal pesquisa foram bastante simples. O primeiro foi identificar o perfil geral do visitante, e o segundo, verificar os parâmetros da estada deste visitante na cidade de São Paulo. Segundo dados fornecidos pela polícia militar, o número de visitantes foi de, aproximadamente, 200 mil.

Embora não se tratasse de uma pesquisa probabilística, os resultados obtidos revelaram aspectos bastante curiosos. O primeiro deles refere-se à origem dos visitantes: 7,6\% deles vieram de fora do Município de São Paulo. Em termos percentuais, pode parecer pouco, mas, posto o universo de 200 mil, cerca de 15,2 mil pessoas vieram de fora. As cidades limítrofes ganharam realce: Osasco, Guarulhos, Itaquaquecetuba, Poá, Santana do Parnaíba e Cotia; porém constam visitantes de Santos, Mongaguá, São José dos Campos e Pinhal.

Pela prospecção, $100 \%$ vão e voltam no mesmo dia, não utilizando assim os meios de hospedagem que a cidade oferece. Como dedução, pode-se dizer que, se houve o uso de algum equipamento, este se limitou aos ônibus normais de linha.

É bem verdade que a escolaridade pode ter tido influência neste fenômeno, pois $45 \%$ possuíam apenas o primeiro grau completo; $50 \%$, o segundo grau completo; e apenas $5 \%$, o curso superior completo (Figura 1). Como viés nas respostas, possivelmente os que afirmaram possuir o primeiro grau completo sentiram-se constrangidos em dizer que sua escolaridade era bastante baixa, porém esta é uma conjectura que não pode ser desprezada.

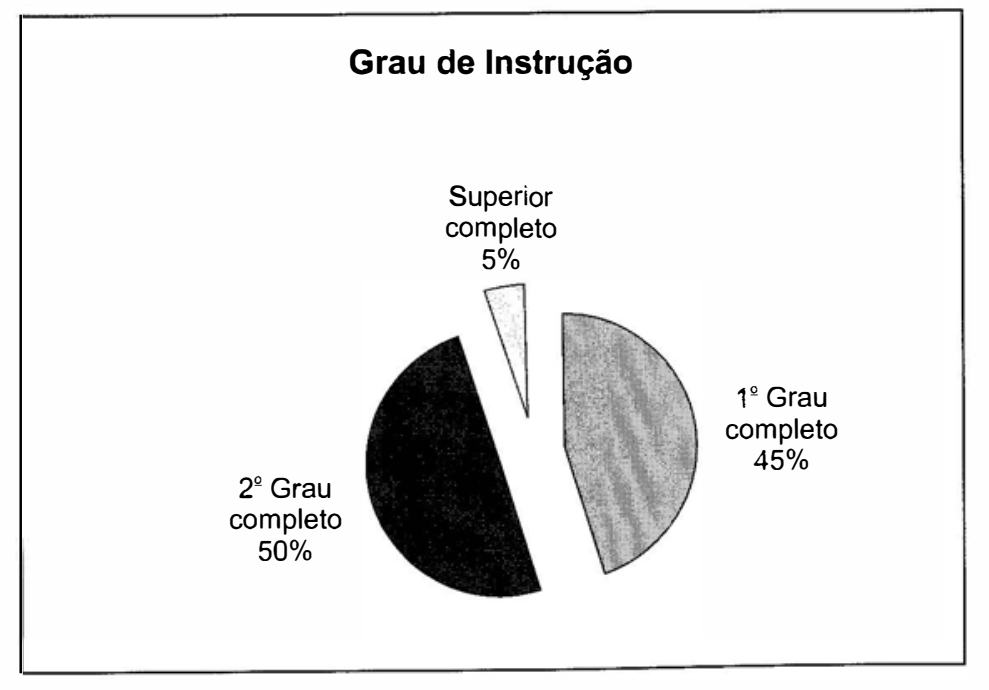

Figura 1. Gráfico - Grau de instrução 
A faixa etária também chama a atenção: 100\% encontram-se entre 45 e 60 anos, ressalvando-se, mais uma vez, a pequena amostragem. O cruzamento das duas variáveis pode levar à conclusão de que a baixa escolaridade, juntamente com a faixa etária, deu, em decorrência, um baixo padrão de consumo na cidade.

As compras limitaram-se ao comércio informal que se formou nas imediaçōes da capela. Artefatos de preço reduzido, como medalhas do santo e velas, representaram $40 \%$ dos produtos adquiridos pelos visitantes. Restaurantes não foram utilizados, pois $80 \%$ alimentaram-se de lanches em barracas improvisadas no mesmo local, e 20\% sequer compraram um lanche (Figura 2).

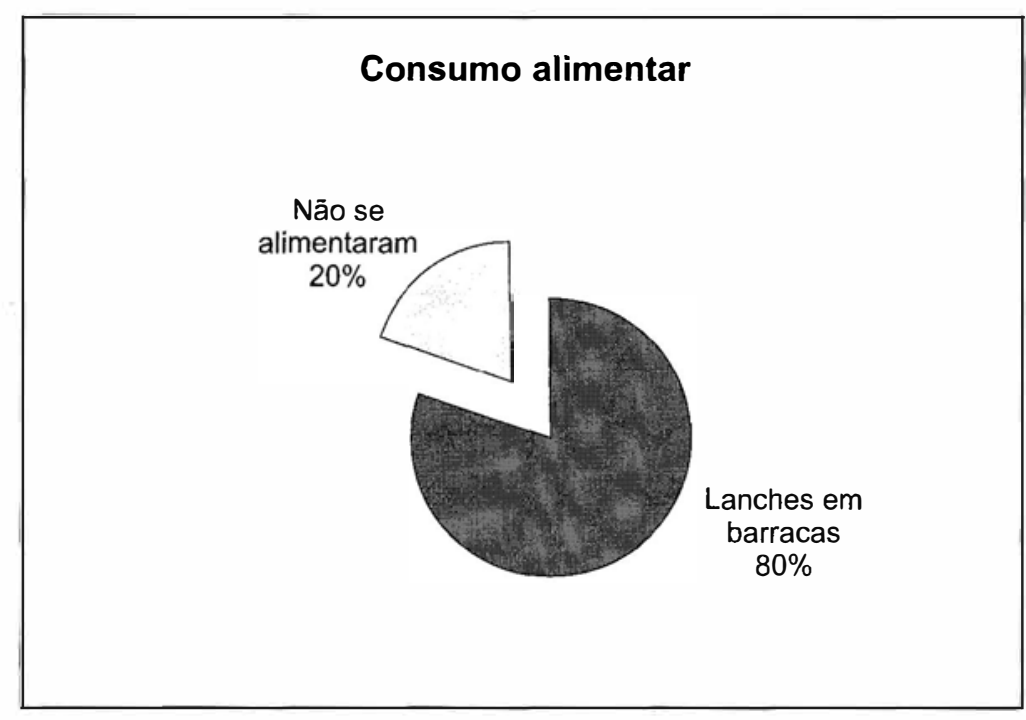

Figura 2. Gráfico - Consumo alimentar

O público, ao que tudo indica, é bastante fiel à sua devoção, uma vez que $60 \%$ dos visitantes visitaram a capela de cinco a seis vezes; $20 \%$, duas vezes; e 20\%; pela primeira vez.

A resposta a uma pergunta do questionário chama bastante atenção. Quando indagado se o devoto veio por obrigação ao santo ou por prazer, a resposta foi unânime: ambos os motivos.

Com a presença do prazer, embora realizando uma obrigação, cabe o questionamento sobre as antigas definiçōes de lazer. Se este pressupōe o despojamento das obrigaçōes, como podem ser qualificadas as açōes que, não obstante comportarem o compromisso religioso, são realizadas de maneira prazerosa? Disso resulta outra pergunta: será que uma nova concepção de lazer não deveria ter um foco mais voltado ao caráter qualitativo, que, neste caso, é o prazer?

\section{Considerações finais}

Delimitado o termo, não cabe emoldurá-lo nas categorias convencionais relativas a algum juízo de valor. Isso se torna, aliás, perigoso, uma vez que julgar o turismo de não-mercado como bom ou ruim, conveniente ou inconveniente, dependerá da leitura comprometida dos diversos protagonistas envolvidos nos diferentes lados: turistas, destinações, comércio informal e proprietário de equipamentos turísticos, entre outros.

O turismo de não-mercado egoísta, predatório, impactante, poderá continuar existindo. Porém, mais odiado do que amado, tenderá, com o tempo, a ser enquadrado em regras rígidas que minimizarão seus malefícios. E quem se importará com isso, a não ser os atores que verão seus "direitos" restringidos?

Não hádúvida, contudo, de que certas manifestaçōes do turismo de não-mercado podem provocar simpatia pelo seu caráter de fuga dos modelos convencionais do grande mercado. $\mathrm{O}$ ato de viajar, em todos os tempos, sempre imprimiu um sentido de liberdade, e esta se expande do deleite à própria liberdade de não gastar, não usar equipamentos turísticos nem seguir as regras que permitem facilidades.

Este é um tema em que qualquer proposta torna-se tendenciosa.A sugestão de colocar cabresto neste fenômeno esbarra em, pelo menos, dois grandes problemas: pelo seu caráter marginal, improvisado e, até certo ponto, imprevisível, torna-se muito difícil transformá-lo em turismo de mercado; mas colocar cabresto já é uma atitude dogmática, pois parte do princípio polêmico de que absolutamente nada que esteja fora do mercado convencional tem o direito de existir.

\section{Referências bibliográficas}

BORG, Jan Van der. 2001. Gestão de turismo em Veneza ou como lidar com o sucesso. In: TYLER, Duncan, GUERRIER, Yvone \& ROBERTSON, Martin. Gestão de turismo municipal: teoria e prática de planejamento turístico nos centros urbanos. São Paulo: Futura.

COOPER, Chris et al. 2001. Turismo, principios e pratica. 2. ed. Porto Alegre: Bookman.

DAVIDSON, Thomas Lea. O que são viagens e turismo: constitui de fato um setor? In: THEOBALD, William F. (Org.). Turismo global. São Paulo: SENAC.

KRIPPENDORF, Jost. 2001. Sociologia do turismo: para uma nova compreensão do lazer e das viagens. São Paulo: Aleph. 
32 Turismo em Análise, v. 18, n. 1, p. 24-32, maio 2007

LEIPER, N. 1979. The framework of tourism. Annals of Tourism Research, v. 6, n. 4.

SMITH, S. L. J. 1989. Tourism analysis. A handbook. Longman: Harlow, 1989

Recebido em: 20/08/2005.

Aprovado em: 10/01/2006. 